\title{
KLASYFIKACJA DYNAMICZNA REGIONÓW UNII EUROPEJSKIEJ SZCZEBLA NUTS 2 POD WZGLĘDEM WRAŻLIWOŚCI NA KRYZYS EKONOMICZNY W OBSZARZE RYNEK PRACY ${ }^{5}$
}

\begin{abstract}
Ocena przyczyn oraz skutków kryzysu ekonomicznego może obejmować różne poziomy gospodarowania. Analizy możliwe są zarówno na szczeblu makro, jak i na szczeblach pośrednich (to jest zarówno na poziomie przedsiębiorstw, jak i w skali regionów). Każda z wymienionych perspektyw ma swoją specyfikę określającą czynniki i uwarunkowania wrażliwości na kryzys badanych gospodarek krajów, firm czy też regionów. Ze względu na możliwości pomiaru (dane statystyczne, których zakres jest inny, m.in. w wyniku możliwości statystyki publicznej) niezbędne są również odrębne podejścia badawcze charakterystyczne dla danego poziomu.

W proponowanym podejściu badawczym do obszarów wrażliwości na kryzys ekonomiczny regionów zaliczono takie sfery jak: gospodarka, gospodarstwa domowe i rynek pracy. W artykule przedstawiono wyniki klasyfikacji dynamicznej (lata 2005-2011) regionów Unii Europejskiej szczebla NUTS 2 w jednym z trzech obszarów wrażliwości na kryzys ekonomiczny, którym jest rynek pracy. Zmienne diagnostyczne stanowiły: stopa zatrudnienia i stopa bezrobocia oraz tempo zmian obu tych wskaźników. Wykorzystano podejście dynamiczne, w którym zakłada się, że te same obiekty badania (regiony) występują $\mathrm{w}$ zbiorze wielokrotnie poddanym klasyfikacji i są traktowane jako odrębne jednostki taksonomiczne (obiekto-okresy) - ze względu na realizacje wartości cech w kolejnych latach. Takie podejście pozwoliło na wyodrębnienie grup regionów o podobnych właściwościach ze względu na badane wskaźniki wrażliwości na kryzys ekonomiczny oraz umożliwiło ocenę zmian przypisania regionów do klas w czasie.

Słowa kluczowe: regiony NUTS 2, klasyfikacja dynamiczna, wrażliwość na kryzys.
\end{abstract}

${ }^{1}$ Dr hab. Małgorzata Markowska, Wydział Ekonomii, Zarządzania i Turystyki, Uniwersytet Ekonomiczny, Wrocław

${ }^{2}$ Prof. dr hab. Andrzej Sokołowski, Wydział Zarządzania, Uniwersytet Ekonomiczny, Kraków

${ }^{3}$ Prof. dr hab. Danuta Strahl, Wydział Ekonomii, Zarządzania i Turystyki, Uniwersytet Ekonomiczny, Wrocław

${ }^{4} \mathrm{Dr}$ Marek Sobolewski, Katedra Metod Ilościowych, Wydział Zarządzania, Politechnika Rzeszowska, al. Powstańców Warszawy 8, 35-959 Rzeszów, tel. (017) 865-16-02, autor korespondencyjny, e-mail: msobolew@ prz.edu.pl

${ }^{5}$ Projekt finansowany ze środków NCN (DEC-2013/09/B/HS4/00509). 


\section{WPROWADZENIE}

Zagadnienia związane z wrażliwością/odpornością regionów na zjawiska kryzysowe stanowią ważny element zainteresowań rosnącej grupy badaczy ${ }^{6}$. Obserwowane jest poddawanie się gospodarczym zawirowaniom $\mathrm{w}$ jednych regionach $\mathrm{i}$ radzenie sobie $\mathrm{z}$ załamaniem gospodarczym w drugich, dodatkowo w obrębie obu tych grup skala tych reakcji jest odmienna.

Celem artykułu jest klasyfikacja regionów UE szczebla NUTS 2 pod względem stopnia wrażliwości na kryzys ekonomiczny w obszarze rynek pracy z uwzględnieniem takich charakterystyk jak: stopa zatrudnienia i bezrobocia oraz wskaźniki tempa ich zmian w latach 2005-2011.

\section{METODA BADAWCZA - KRÓTKA CHARAKTERYSTYKA}

Przegląd badań w zakresie oceny odporności i wrażliwości regionów na wpływ otoczenia (np. gospodarczego) przedstawiła Markowska ${ }^{7}$. Propozycję podejścia metodologicznego do m.in. identyfikacji obszarów wrażliwości (gospodarka, rynek pracy, gospodarstwa domowe), wyboru zmiennych oraz ich możliwy zestaw znaleźć można w pracy Strahl i Sokołowskiego ${ }^{8}$.

Idea wykorzystanej w artykule klasyfikacji dynamicznej znajduje się w pracy Markowskiej $^{9}$, w skrócie można ją opisać następująco jej najważniejsze założenia to: 1) identyfikacja obszarów wrażliwości i ustalenie listy zmiennych; 2) wyznaczenie median cech na podstawie wszystkich lat obserwacji; 3) „standaryzacja” (podzielenie przez medianę - medianę danych przestrzenno-czasowych ${ }^{10}$ ); 4) wykorzystanie taksonomii dynamicznej, w tym ustalenie liczby grup - przez poddanie kostki danych (obiekty regiony rozpatrywane łącznie - dla wszystkich lat razem) analizie - za pomocą metody

${ }^{6}$ M. Markowska, Ocena zależności między rozwojem inteligentnym a odpornościa na kryzys ekonomiczny w wymiarze regionalnym - przeglad badań, [w:] Gospodarka regionalna $w$ teorii $i$ praktyce, red. D. Strahl, A. Raszkowski i D. Głuszczuk, Prace Naukowe Uniwersytetu Ekonomicznego we Wrocławiu nr 333, Wrocław 2014, s. 22-32; M. Markowska, The vulnerability of regions to economic crisis - measurement problems, [w:] Regional economy and policy. Territories and cities, red. P. Hlavacek, P. Olsowa, Jan Evangelista Purkyne University in Usti nad Labem Usti nad Labem 2014, 38-47.

${ }^{7}$ M. Markowska, Ocena zależności między rozwojem inteligentnym a odpornościa na kryzys ekonomiczny $w$ wymiarze regionalnym - przeglad badań, [w:] Gospodarka regionalna $w$ teorii $i$ praktyce, red. D. Strahl, A. Raszkowski i D. Głuszczuk, Prace Naukowe Uniwersytetu Ekonomicznego we Wrocławiu nr 333, Wrocław 2014, s. 22-32.

${ }^{8}$ D. Strahl, A. Sokołowski, Propozycja podejścia metodologicznego do oceny zależności między inteligentnym rozwojem a wrażliwościa na kryzys ekonomiczny $w$ wymiarze regionalnym, [w:] Problemy rozwoju regionalnego i lokalnego, red. E. Sobczak, B. Bal-Domańska, M. Obrębalski, Prace Naukowe Uniwersytetu Ekonomicznego we Wrocławiu nr 331, Wrocław 2014, s. 181-190.

${ }^{9}$ M. Markowska, Dynamiczna taksonomia innowacyjności regionów, Wydawnictwo Uniwersytetu Ekonomicznego we Wrocławiu, Monografie i Opracowania 221, Wrocław 2012.

${ }^{10}$ Zalety wykorzystanej standaryzacji: pozostawia znak tempa zmian: ujemny to pogorszenie, plus poprawa; sprowadza wszystkie zmienne do jednakowej ważności i chociaż formalnie nie jest to system ważenia, to można powiedzieć, że w początkowym etapie tempa oryginalne są ważone wagami $1 / \mathrm{Me}$. Ponadto pozostawia wartości odstające zdecydowanie różniące się od pozostałych (nie powodują sztucznej kompresji rozkładu, jak w wypadku dzielenia przez odchylenie standardowe) 
Warda oraz ostateczna klasyfikacja metodą $k$-średnich; 5) interpretacja wyników: analiza merytoryczno-czasowa dla krajów i geograficzno-czasowa dla grup.

Opisany schemat postępowania wykorzystano do klasyfikacji regionów Unii Europejskiej (UE) szczebla NUTS 2 pod względem wszystkich obszarów wrażliwości na kryzys ekonomiczny potraktowanych łącznie ${ }^{11}$, w obszarze gospodarki ${ }^{12}$ oraz w obszarze gospodarstw domowych ${ }^{13}$. Umożliwia on śledzenie „ścieżki” każdego regionu i ocenę zmian w klasyfikacji w ujęciu dynamicznym, a dzięki odpowiedniemu doborowi zmiennych diagnostycznych - identyfikację grup regionów o podobnych własnościach i zbliżonych trajektoriach „trwania” w klasie lub „wędrówki” pomiędzy klasami.

\section{WYNIKI KLASYFIKACJI DYNAMICZNEJ UNIJNYCH REGIONÓW NUTS 2 ZE WZGLĘU NA WRAŻLIWOŚĆ NA KRYZYS EKONOMICZNY W OBSZARZE: RYNEK PRACY}

Do oceny wrażliwości na kryzys w jednym z obszarów - rynek pracy - wykorzystano cztery zmienne: stopę zatrudnienia (SZ), tempo zmian stopy zatrudnienia (TZ_SZ), stopę bezrobocia (SB - destymulanta) oraz tempo zmian stopy bezrobocia, przeliczone na stymulantę, czyli dodatnia liczba to spadek bezrobocia (TZ_SB). Obiekty badania stanowią regiony ${ }^{14}$ UE szczebla NUTS $2^{15}$, dane pochodzą z lat 2005-2011, przy czym po uwzględnieniu obliczeń niezbędnych do ustalenia temp zmian dalsze analizy prowadzono dla danych z lat 2006-2011.

Ocenę wartości diagnostycznej zmiennych przeprowadzono, analizując spadki stóp zatrudnienia i wzrosty stóp bezrobocia w 264 regionach UE: w roku 2009 w 205 regionach zanotowano spadek stopy zatrudnienia, a w 238 wzrost stopy bezrobocia, w 2010 niższa niż w roku poprzednim stopa zatrudnienia była w 159 regionach, a w 2011 w 110. Natomiast wzrost stopy bezrobocia dotyczył w 2010 r. 171 regionów, w 2011 zaś - 114. Zmienne wybrane do oceny wrażliwości regionów na kryzys w obszarze rynek pracy mają wysoką moc diagnostyczną $\mathrm{i}$ biorą udział $\mathrm{w}$ grupowaniu regionów UE szczebla NUTS 2.

Zgodnie z opisanym wcześniej podejściem badawczym wstępnie wyznaczono liczbę grup, wykorzystując metodę Warda (rys. 1), a do ostatecznej klasyfikacji zastosowano

\footnotetext{
${ }^{11}$ M. Markowska, D. Strahl, Wykorzystanie klasyfikacji dynamicznej do identyfikacji wrażliwości na kryzys ekonomiczny unijnych regionów szczebla NUTS 2, [w:] Taksonomia, red. M. Walesiak, K. Jajuga, Prace Naukowe Uniwersytetu Ekonomicznego we Wrocławiu nr 385, Wrocław 2015, s. 166-177.

${ }^{12}$ M. Markowska, D. Strahl, A. Sokołowski, M. Sobolewski, Klasyfikacja dynamiczna regionów Unii Europejskiej szczebla NUTS 2 z uwagi na wrażliwość na kryzys ekonomiczny (obszar: zmiany w gospodarce), [w:] Problemy rozwoju regionalnego i lokalnego, red. M. Markowska, D. Głuszczuk, A. Sztando, Prace Naukowe Uniwersytetu Ekonomicznego we Wrocławiu nr 393, Wrocław 2015, s. 32-44.

${ }^{13}$ M. Markowska, Ocena wrażliwości na kryzys gospodarstw domowych $w$ unijnych regionach analiza przestrzenno-czasowa, [w:] Problemy rozwoju regionalnego i lokalnego, red. M. Markowska, D. Głuszczuk i A. Sztando, Prace Naukowe Uniwersytetu Ekonomicznego we Wrocławiu nr 393, Wrocław 2015, s. 53-66.

${ }^{14}$ Regions in the European Union. Nomenclature of territorial unit for statistics NUTS 2010/EU-27, Methodologies and Working Papers, European Commission, Luxembourg 2011.

${ }^{15}$ Bez chorwackich (4) oraz zamorskich: francuskich (4) i hiszpańskich (2).
} 
metodę $k$-średnich. W tabeli 1 zestawiono liczbę obiektów w klasie (ogółem i w latach) oraz wartości średnie zmiennych.

Rysunek 1. Dendrogram z metody Warda - wskazanie optymalnego podziału na klasy

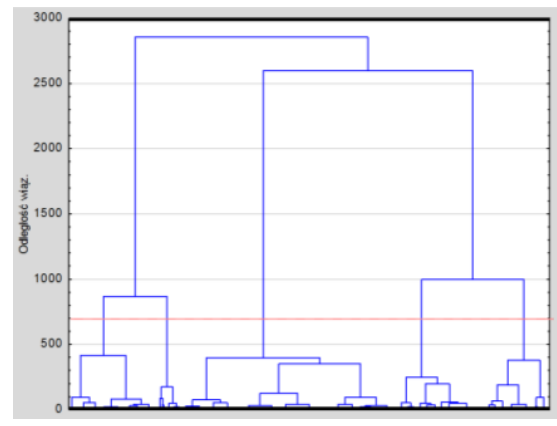

Źródło: opracowanie własne.

Tabela 1. Liczba obiekto-okresów w klasach i wartości średnie analizowanych wskaźników

\begin{tabular}{|c|c|c|c|c|c|c|c|c|c|c|c|c|}
\hline \multirow{2}{*}{ Grupa } & \multicolumn{2}{|c|}{ Liczba } & Procent & \multirow{2}{*}{ SZ } & \multirow{2}{*}{ TZ_SZ } & \multirow{2}{*}{ SB } & \multirow{2}{*}{ TZ_SB } & \multicolumn{4}{|c|}{ Liczba obiektów w klasie w roku } \\
\cline { 2 - 8 } & \multicolumn{2}{|c|}{ obiekto-okresów } & & & $\mathbf{2 0 0 6}$ & $\mathbf{2 0 0 7}$ & $\mathbf{2 0 0 8}$ & $\mathbf{2 0 0 9}$ & $\mathbf{2 0 1 0}$ & $\mathbf{2 0 1 1}$ \\
\hline $\mathbf{1}$ & 602 & 38,0 & 70,92 & 1,09 & 5,37 & 8,63 & 115 & 142 & 128 & 26 & 78 & 113 \\
\hline $\mathbf{2}$ & 247 & 15,6 & 55,78 & $-0,63$ & 11,88 & $-5,44$ & 30 & 23 & 28 & 44 & 61 & 61 \\
\hline $\mathbf{3}$ & 361 & 22,8 & 68,38 & $-1,54$ & 6,76 & $-24,41$ & 30 & 21 & 50 & 153 & 75 & 32 \\
\hline $\mathbf{4}$ & 291 & 18,4 & 61,67 & 2,87 & 9,58 & 12,51 & 88 & 78 & 54 & 10 & 24 & 37 \\
\hline $\mathbf{5}$ & 83 & 5,2 & 58,53 & $-5,23$ & 15,91 & $-45,60$ & 1 & 4 & 31 & 0 & 26 & 21 \\
\hline
\end{tabular}

SZ - wskaźnik zatrudnienia, TZ_SZ - zmiana wskaźnika zatrudnienia,

SB - stopa bezrobocia, TZ_SB - tempo zmian stopy bezrobocia

Źródło: opracowanie własne.

Krótką charakterystykę grup przedstawiono poniżej, a przynależność regionów (wykorzystano akronimy, których wyjaśnienia zamieszczono na końcu artykułu) do klas można odszukać w tabelach 2-6:

- $\quad$ grupa 1 - najwyższa stopa zatrudnienia i najniższe bezrobocie, ponadto wykazują one pozytywną tendencję: zwiększające się zatrudnienie (średnie dodatnie tempo zmian stopy zatrudnienia) i zmniejszające się bezrobocie;

- grupa 2 - najmniejsza stopa zatrudnienia i stosunkowo duże bezrobocie;

- $\quad$ grupa 3 - dobra sytuacja co do poziomu stóp (druga pozycja wśród grup), ale też druga pozycja (ale druga najgorsza), jeżeli chodzi o tempa pogarszania się tych wskaźników;

- $\quad$ grupa 4 - najlepsze tempa poprawy;

- $\quad$ grupa 5 - najszybsze spadki zatrudnienia i bezrobocia; najwyższe bezrobocie i niemal najniższa stopa zatrudnienia. 
Klasyfikacja dynamiczna...

Tabela 2. Regiony w klasie pierwszej

\begin{tabular}{|c|c|c|c|c|c|c|}
\hline \multirow{2}{*}{ Kraj (liczba regionów z kraju): kod regionu } & \multicolumn{6}{|c|}{ Przynależność regionu do klasy } \\
\hline & 2006 & 2007 & 2008 & 2009 & 2010 & 2011 \\
\hline DE (4): DE13, DE71, DE72, DEB2; AT(1): AT33 & 1 & 1 & 1 & 1 & 1 & 1 \\
\hline IT (1): ITH2; NL (2): NL22, NL23 & 1 & 1 & 1 & 1 & 0 & 1 \\
\hline $\begin{array}{l}\text { BE (2): BE21, BE25; DE (10): DE11, DE12, DE14, DE22, DE23, DE24, DE25, } \\
\text { DE26, DE27, DEB1; FR (1): FR42; AT (7): AT11, AT12, AT21, AT22, AT31, } \\
\text { AT32, AT34; FI (2): FI1B, FI20; SE (4): SE11, SE21, SE22, SE23; UK (2): UKJ1, } \\
\text { UKJ2 }\end{array}$ & 1 & 1 & 1 & 0 & 1 & 1 \\
\hline DE (4): DE60, DE70, DE93, DEB3; AT (1): AT13 & 0 & 1 & 1 & 1 & 1 & 1 \\
\hline DE (5): DE91, DE92, DE94, DEA1, DEA2 & 0 & 0 & 1 & 1 & 1 & 1 \\
\hline BE (1): BE22; CZ (1): CZ02; DE (2): DEA4, DEF0; IT (1): ITI2; FR (1): FR52 & 0 & 1 & 1 & 0 & 1 & 1 \\
\hline UK (1): UKK4 & 1 & 0 & 1 & 0 & 1 & 1 \\
\hline UK (1): UKM5 & 1 & 0 & 1 & 1 & 1 & 0 \\
\hline BE (1): BE24; IT (1): ITH4; SE (1) SE31; UK (1): UKN0 & 1 & 1 & 0 & 0 & 1 & 1 \\
\hline NL (1): NL34; LU00 & 1 & 1 & 0 & 1 & 1 & 0 \\
\hline $\begin{array}{l}\text { BE (1): BE23; CZ (4): CZ01, CZ02, CZ03, CZ06; DK (4): DK01, DK02, DK03, } \\
\text { DK04; FR (1): FR71; IT (2): ITH3, ITH4; NL (8): NL12, NL13, NL21, NL31, } \\
\text { NL32, NL33, NL41, NL42; SK (1): SK01; FI (2): FI19, FI1C; SE (1): SE12; UK } \\
\text { (2): UKE1, UKJ3 }\end{array}$ & 1 & 1 & 1 & 0 & 0 & 1 \\
\hline FR (2): FR24, FR53; IT (2): ITC2, ITH1; UK (1): UKK2 & 1 & 1 & 1 & 0 & 1 & 0 \\
\hline $\begin{array}{l}\text { ES (1): ES21; IT (1): ITC4; CY00; NL (1): NL11; PT (2): PT16, PT17; SI (2): SI01, } \\
\text { SI02 }\end{array}$ & 1 & 1 & 1 & 0 & 0 & 0 \\
\hline IT (1): ITI3; UK (1): UKK1 & 1 & 1 & 0 & 0 & 1 & 0 \\
\hline SE (2): SE32, SE33; UK (1): UKF2 & 1 & 1 & 0 & 0 & 0 & 1 \\
\hline FR (2): FR10, FR63 & 1 & 0 & 1 & 0 & 0 & 1 \\
\hline UK (1): UKD6 & 1 & 0 & 0 & 0 & 1 & 1 \\
\hline UK (5): UKD1, UKD4, UKH2, UKI1, UKM6 & 0 & 1 & 1 & 0 & 1 & 0 \\
\hline UK (5): UKE2, UKG1, UKH1, UKL2, UKM2 & 0 & 1 & 1 & 0 & 0 & 1 \\
\hline DE (2): DEA3, DEC0 & 0 & 0 & 1 & 0 & 1 & 1 \\
\hline DE (2): DE40, DEG0 & 0 & 0 & 0 & 1 & 1 & 1 \\
\hline $\begin{array}{l}\text { IE (2): IE01, IE02; EL (1): EL43; ES (5): ES22, ES23,ES24, ES30, ES51; FR (2): } \\
\text { FR25, FR51; IT (2): ITC1, ITI1; HU (1): HU22; PT (1): PT18; UK (3): UKC1, } \\
\text { UKC2, UKM3 }\end{array}$ & 1 & 1 & 0 & 0 & 0 & 0 \\
\hline DK (1): DK05; PT (2): PT11, PT15 & 1 & 0 & 1 & 0 & 0 & 0 \\
\hline UK (1): UKD3 & 1 & 0 & 0 & 0 & 1 & 0 \\
\hline $\begin{array}{l}\text { BG (1): BG41; CZ (1): CZ07; EL (1): EL25; HU (1): HU10; RO (1): RO32; UK (1): } \\
\text { UKJ4 }\end{array}$ & 0 & 1 & 1 & 0 & 0 & 0 \\
\hline IT (1): ITC3; UK(1): UKH3 & 0 & 1 & 0 & 0 & 0 & 1 \\
\hline PT (1): PT30; UK (1): UKF3 & 0 & 0 & 1 & 0 & 1 & 0 \\
\hline UK (2): UKF1, UKG2 & 0 & 0 & 1 & 0 & 0 & 1 \\
\hline UK (1): UKK3 & 0 & 0 & 0 & 1 & 0 & 1 \\
\hline DE (2): DEA5, DED2 & 0 & 0 & 0 & 0 & 1 & 1 \\
\hline ES (1): ES53; PT (1): PT20 & 1 & 0 & 0 & 0 & 0 & 0 \\
\hline $\begin{array}{l}\text { EE00; ES (2): ES13, ES52; LV00; LT00; HU(1): HU21; UK (3): UKE3, UKI1, } \\
\text { UKL1 }\end{array}$ & 0 & 1 & 0 & 0 & 0 & 0 \\
\hline BE (1): BE31; EL (1): EL41; FR (4): FR21, FR26, FR43, FR62; RO (1): RO21 & 0 & 0 & 1 & 0 & 0 & 0 \\
\hline PL (1): PL12 & 0 & 0 & 0 & 1 & 0 & 0 \\
\hline BE (1): BE31; DE (5): DE34, DE50, DE80, DED4, DED5, DED0 & 0 & 0 & 0 & 0 & 0 & 1 \\
\hline Ogólem & 115 & 142 & 128 & 26 & 78 & 113 \\
\hline
\end{tabular}

Źródło: opracowanie własne 
Tabela 3. Regiony w klasie drugiej

\begin{tabular}{|c|c|c|c|c|c|c|}
\hline \multirow{2}{*}{ Kraj (liczba regionów z kraju): kod regionu } & \multicolumn{6}{|c|}{ Przynależność regionu do klasy } \\
\hline & 2006 & 2007 & 2008 & 2009 & 2010 & 2011 \\
\hline $\begin{array}{l}\text { BE (1): BE10; FR (1): FR30; IT (4): ITF3, ITF4, ITF6, ITG1; HU (3): HU23, } \\
\text { HU31, HU32 }\end{array}$ & 1 & 1 & 1 & 1 & 1 & 1 \\
\hline BE (1): BE33 & 1 & 1 & 1 & 1 & 1 & 0 \\
\hline BE (1): BE32; IT (1): ITF2 & 1 & 0 & 1 & 1 & 1 & 1 \\
\hline IT (2): ITF5, ITG2 & 0 & 1 & 1 & 1 & 1 & 1 \\
\hline RO (1): RO41 & 1 & 1 & 0 & 1 & 1 & 0 \\
\hline EL (1): EL23 & 1 & 0 & 1 & 1 & 1 & 0 \\
\hline BE (1): BE35; HU (1): HU33 & 1 & 0 & 1 & 1 & 0 & 1 \\
\hline FR (1): FR82; PL (2): PL42, PL61 & 1 & 0 & 0 & 1 & 1 & 1 \\
\hline EL (1): EL24 & 0 & 1 & 1 & 1 & 1 & 0 \\
\hline RO (2): RO12, RO22; SK (1): SK03 & 0 & 1 & 0 & 1 & 1 & 1 \\
\hline IT (1): ITI4; PL (1): PL31 & 0 & 0 & 1 & 1 & 1 & 1 \\
\hline FR (1): FR81 & 1 & 0 & 1 & 0 & 1 & 0 \\
\hline BG (1): BG32 & 1 & 0 & 0 & 1 & 0 & 1 \\
\hline EL (1): EL12 & 0 & 1 & 1 & 1 & 0 & 0 \\
\hline EL (1): EL21; FR (1): FR23 & 0 & 1 & 0 & 1 & 1 & 0 \\
\hline EL (1): EL14; RO (1): RO42 & 0 & 0 & 1 & 1 & 1 & 0 \\
\hline PL (4): PL32, PL33, PL51, PL62 & 0 & 0 & 0 & 1 & 1 & 1 \\
\hline FR (1): FR83 & 1 & 1 & 0 & 0 & 0 & 0 \\
\hline DE (1): DE30 & 1 & 0 & 1 & 0 & 0 & 0 \\
\hline MT00 & 1 & 0 & 0 & 1 & 0 & 0 \\
\hline CZ (2): CZ04, CZ08; FR (1): FR22 & 1 & 0 & 0 & 0 & 1 & 0 \\
\hline EL(1): EL42; FR (1): FR41 & 1 & 0 & 0 & 0 & 0 & 1 \\
\hline EL (1): EL13 & 0 & 1 & 1 & 0 & 0 & 0 \\
\hline ES (1): ES43 & 0 & 0 & 1 & 0 & 1 & 0 \\
\hline PL (2): PL43, PL52 & 0 & 0 & 0 & 1 & 1 & 0 \\
\hline BG (1): BG31; SK (1): SK04 & 0 & 0 & 0 & 1 & 0 & 1 \\
\hline $\begin{array}{l}\text { IE (1): IE01; ES (6): ES13, ES22, ES23, ES30, ES41, ES51; PL (2): PL21, PL41; } \\
\text { PT (2): PT11, PT18 }\end{array}$ & 0 & 0 & 0 & 0 & 1 & 1 \\
\hline PL (1): PL34 & 1 & 0 & 0 & 0 & 0 & 0 \\
\hline ES (1): ES61 & 0 & 1 & 0 & 0 & 0 & 0 \\
\hline RO (1): RO11 & 0 & 0 & 1 & 0 & 0 & 0 \\
\hline BE (1): BE34; EL (1): EL11 & 0 & 0 & 0 & 1 & 0 & 0 \\
\hline $\begin{array}{l}\text { IT (1): ITF1; LV00; HU (2): HU21, HU22; PL (2): PL11, PL22; RO (1): RO31; SK } \\
\text { (1): SK02; UK (2): UKD7, UKL1 }\end{array}$ & 0 & 0 & 0 & 0 & 1 & 0 \\
\hline $\begin{array}{l}\text { BG (3): BG33, BG34, BG42; IE (1): IE02; EL (1): EL22; ES (6): ES11, ES12, } \\
\text { ES21, ES24, ES42, ES70; FR (2): FR21, FR25; HU (1): HU10; PL (1): PL63; PT } \\
\text { (2): PT15, PT17; UK (1): UKG3 }\end{array}$ & 0 & 0 & 0 & 0 & 0 & 1 \\
\hline $\begin{array}{ll}\text { Ogólem } \\
\end{array}$ & 30 & 23 & 28 & 44 & 61 & 61 \\
\hline
\end{tabular}

Źródło: opracowanie własne

Tabela 4. Regiony w klasie trzeciej

\begin{tabular}{|l|c|c|c|c|c|c|}
\hline \multicolumn{1}{|c|}{ Kraj (liczba regionów z kraju): kod regionu } & \multicolumn{5}{|c|}{ Przynależność regionu do klasy } \\
\cline { 2 - 6 } & $\mathbf{2 0 0 6}$ & $\mathbf{2 0 0 7}$ & $\mathbf{2 0 0 8}$ & $\mathbf{2 0 0 9}$ & $\mathbf{2 0 1 0}$ & $\mathbf{2 0 1 1}$ \\
\hline UK (1): UKE4 & 1 & 1 & 1 & 1 & 1 & 1 \\
\hline FR (1): FR72 & 1 & 1 & 0 & 1 & 1 & 1 \\
\hline UK (1): UKD7 & 1 & 1 & 1 & 1 & 0 & 0 \\
\hline UK (1): UKK3 & 1 & 1 & 1 & 0 & 1 & 0 \\
\hline UK (2): UKF1, UKG2 & 1 & 1 & 0 & 1 & 1 & 0 \\
\hline FR (1): FR62; UK (1): UKF3 & 1 & 1 & 0 & 1 & 0 & 1 \\
\hline UK (1): UKH3 & 1 & 0 & 1 & 1 & 1 & 0 \\
\hline UK (1): UKE3 & 1 & 0 & 1 & 1 & 0 & 1 \\
\hline UK (1): UKJ4 & 1 & 0 & 0 & 1 & 1 & 1 \\
\hline PT (1): PT20 & 0 & 1 & 1 & 1 & 1 & 0 \\
\hline UK (1): UKD3 & 0 & 1 & 1 & 1 & 0 & 1 \\
\hline DK (1): DK05 & 0 & 1 & 0 & 1 & 1 & 1 \\
\hline FR (1): FR51; IT (1): ITI1 & 0 & 0 & 1 & 1 & 1 & 1 \\
\hline UK (1): UKG3 & 1 & 1 & 1 & 0 & 0 & 0 \\
\hline
\end{tabular}




\begin{tabular}{|c|c|c|c|c|c|c|}
\hline \multirow{2}{*}{ Kraj (liczba regionów z kraju): kod regionu } & \multicolumn{6}{|c|}{ Przynależność regionu do klasy } \\
\hline & 2006 & 2007 & 2008 & 2009 & 2010 & 2011 \\
\hline PT (1): PT30 & 1 & 1 & 0 & 1 & 0 & 0 \\
\hline UK (1): UKL1 & 1 & 0 & 1 & 1 & 0 & 0 \\
\hline FR (1): FR26; HU (1): HU10; UK (5): UKE2, UKG1, UKH1, UKL2, UKM2 & 1 & 0 & 0 & 1 & 1 & 0 \\
\hline UK (5): UKD1, UKD4, UKH2, UKI2, UKM6 & 1 & 0 & 0 & 1 & 0 & 1 \\
\hline UK (1): UKD6 & 0 & 1 & 1 & 1 & 0 & 0 \\
\hline FR (1): FR63 & 0 & 1 & 0 & 1 & 1 & 0 \\
\hline $\begin{array}{l}\text { EL (1): EL42; IT (2): ITC1, ITC3; SE (2): SE32, SE33; UK (3): UKC2, UKF2, } \\
\text { UKM3 }\end{array}$ & 0 & 0 & 1 & 1 & 1 & 0 \\
\hline FR (1): FR61; IT (1): ITI3; UK (1): UKK1 & 0 & 0 & 1 & 1 & 0 & 1 \\
\hline BG (1): BG41; IT (1): ITC4; CY00; NL (1): NL11; RO (1): RO32; SI (2): SI01, SI02 & 0 & 0 & 0 & 1 & 1 & 1 \\
\hline CZ (1): CZ05; FR (1): FR43; RO (1): RO21 & 1 & 0 & 0 & 1 & 0 & 0 \\
\hline ES (1): ES53 & 0 & 1 & 1 & 0 & 0 & 0 \\
\hline FR (1): FR21; PT (2): PT11, PT15; UK (1): UKK4 & 0 & 1 & 0 & 1 & 0 & 0 \\
\hline UK (1): UKM5 & 0 & 1 & 0 & 0 & 0 & 1 \\
\hline BE (1): BE24; IT (1): ITH4; PT(1): PT18; SE (1): SE31; UK (2): UKC1; UKN0 & 0 & 0 & 1 & 1 & 0 & 0 \\
\hline NL (1): NL34 & 0 & 0 & 1 & 0 & 1 & 0 \\
\hline LU00 & 0 & 0 & 1 & 0 & 0 & 1 \\
\hline $\begin{array}{l}\text { BE (2): BE23, BE31; CZ (5): CZ01, CZ02, CZ03, CZ06, CZ07; DK (4): DK01, } \\
\text { DK02, DK03, DK04; EL (2): EL25, EL41; FR (2): FR10, FR25; IT (2): ITH3, ITH5; } \\
\text { NL (8): NL12, NL13, NL21, NL31, NL32, NL33, NL41, NL42; PL(1): PL63; PT (2): } \\
\text { PT16, PT17; SK (1): SK01; FI (2): FI19, FI1C; SE (1): SE12; UK (3): UKE1, UKI1, } \\
\text { UKJ3 }\end{array}$ & 0 & 0 & 0 & 1 & 1 & 0 \\
\hline FR (2): FR24, FR53; IT (2): ITC2, ITH1; UK (1): UKK2 & 0 & 0 & 0 & 1 & 0 & 1 \\
\hline FR (1): FR23 & 1 & 0 & 0 & 0 & 0 & 0 \\
\hline $\begin{array}{l}\text { BE (1): BE34; EE00; IE (2): IE01, IE02; ES (9): ES11, ES13, ES22, ES23, ES24, } \\
\text { ES30, ES41, ES51, ES52; FR (1): FR41; LV00; LT00; HU (2): HU21, HU22 }\end{array}$ & 0 & 0 & 1 & 0 & 0 & 0 \\
\hline $\begin{array}{l}\text { BE (3): BE21, BE22, BE25; BG(2): BG34, BG42; CZ (2): CZ04, CZ08; DE (16): } \\
\text { DE11, DE12, DE14, DE21, DE22, DE23, DE24, DE25, DE26, DE27, DEA3, DEA4, } \\
\text { DEA5, DEB1, DEC0, DEF0; EL (3): EL22, EL30, E142; FR (2): FR42, FR71; IT (1): } \\
\text { ITI2; AT (7): AT11, AT12, AT21, AT22, AT31, AT32, AT34; PL (4): PL11, PL21, } \\
\text { PL34, PL41; RO (2): RO11, RO31; FI (3): FI1B, FI1D, FI20; SE (4): SE11, SE21, } \\
\text { SE22, SE23; UK (2): UKJ1, UKJ2 }\end{array}$ & 0 & 0 & 0 & 1 & 0 & 0 \\
\hline NL (2): NL22, NL23; PL (1): PL12; FR (1): FR52; IT (1): ITH2 & 0 & 0 & 0 & 0 & 1 & 0 \\
\hline Ogólem & 30 & 21 & 50 & 153 & 75 & 32 \\
\hline
\end{tabular}

Źródło: opracowanie własne

Najliczniejszą grupę stanowi pierwsza, a następnie trzecia i czwarta. Najmniej liczną jest natomiast grupa piąta, którą charakteryzuje „chwilowe wyjście” regionów w roku 2008. Regiony stołeczne i te ze stolicą znalazły się w przedstawionej klasyfikacji głównie w pierwszej, a następnie w trzeciej grupie.

Tabela 5. Regiony w klasie czwartej

\begin{tabular}{|c|c|c|c|c|c|c|}
\hline \multirow{2}{*}{ Kraj (liczba regionów z kraju): kod regionu } & \multicolumn{6}{|c|}{ Przynależność regionu do klasy } \\
\hline & 2006 & 2007 & 2008 & 2009 & 2010 & 2011 \\
\hline DE (5): DE50, DE80, DED4, DED5, DEE0 & 1 & 1 & 1 & 1 & 1 & 0 \\
\hline PL (1): PL22 & 1 & 1 & 1 & 1 & 0 & 1 \\
\hline FI (1): FI1D & 1 & 1 & 1 & 0 & 1 & 1 \\
\hline DE (1): DED2 & 1 & 1 & 1 & 1 & 0 & 0 \\
\hline IT (1): ITF1; PL (4): PL11, PL12, PL43, PL52; SK (1): SK02 & 1 & 1 & 1 & 0 & 0 & 1 \\
\hline RO (1): RO11 & 1 & 1 & 0 & 0 & 1 & 1 \\
\hline MT00 & 0 & 1 & 1 & 0 & 1 & 1 \\
\hline DE (1): DE30 & 0 & 1 & 0 & 1 & 1 & 1 \\
\hline FR (1): FR83 & 0 & 0 & 1 & 1 & 1 & 1 \\
\hline BG (4): BG31, BG33, BG34, BG42; DE (3): DE40, DEA5, DEG0; EL & 1 & 1 & 1 & 0 & 0 & 0 \\
\hline
\end{tabular}




\begin{tabular}{|c|c|c|c|c|c|c|}
\hline $\begin{array}{l}\text { EL30; ES (1): ES12; PL (7): PL21, PL32, PL33, PL41, PL51, PL62, PL63; RO (1): } \\
\text { RO31: SK (1): SK04 }\end{array}$ & & & & & & \\
\hline BE (1): BE34; FR (1): FR61 & 1 & 1 & 0 & 0 & 1 & 0 \\
\hline $\mathrm{BE}(1): \mathrm{BE} 31 ; \mathrm{RO}(1): \mathrm{RO} 42$ & 1 & 1 & 0 & 0 & 0 & 1 \\
\hline UK (1): UKI1 & 1 & 0 & 1 & 0 & 0 & 1 \\
\hline CZ (2): CZ04, CZ08; FR (1): FR22; PL (1): PL34 & 0 & 1 & 1 & 0 & 0 & 1 \\
\hline FR (1): FR42; RO (1): RO21 & 0 & 1 & 0 & 0 & 1 & 1 \\
\hline $\begin{array}{l}\text { DE (7): DE91, DE92, DE94, DEA1, DEA2, DEA3, DEC0; EL (2): EL14, EL41; ES } \\
\text { (6): ES11, ES41, ES42, ES43, ES62, ES70; IT (1): ITI4; PL (1): PL31 }\end{array}$ & 1 & 1 & 0 & 0 & 0 & 0 \\
\hline EL (1): EL21; RO (2): RO12, RO22; SK (1): SK03 & 1 & 0 & 1 & 0 & 0 & 0 \\
\hline EL (1): EL13 & 1 & 0 & 0 & 1 & 0 & 0 \\
\hline FR (1): FR21 & 1 & 0 & 0 & 0 & 1 & 0 \\
\hline CZ (1): CZ07; EE00; LV00; LT00; HU (1): HU21 & 1 & 0 & 0 & 0 & 0 & 1 \\
\hline BG (1): BG32; EL (2): EL22, EL42; FR (1): FR82; PL (2): PL42, PL61 & 0 & 1 & 1 & 0 & 0 & 0 \\
\hline BE (1): BE35; FR (1): FR41; HU (1): HU33 & 0 & 1 & 0 & 0 & 1 & 0 \\
\hline FR (2): FR26, FR81 & 0 & 1 & 0 & 0 & 0 & 1 \\
\hline FR (1): FR23; RO (1): RO41 & 0 & 0 & 1 & 0 & 0 & 1 \\
\hline $\begin{array}{l}\text { BE (1): BE22; BG (1): BG41; DE (6): DE60, DE73, DE93, DEA4, DEB3, DEF0; } \\
\text { EL (3): EL12, EL24, EL25; ES (3): ES13, ES52, ES61; FR (1): FR52; IT (4): ITC3, } \\
\text { ITI2, ITF5, ITG2; AT (1): AT13; RO (1): RO32 }\end{array}$ & 1 & 0 & 0 & 0 & 0 & 0 \\
\hline BE (1): BE32; EL (1): EL23; FR (1): FR10; IT (1): ITF2 & 0 & 1 & 0 & 0 & 0 & 0 \\
\hline FR (2): FR25, FR72 & 0 & 0 & 1 & 0 & 0 & 0 \\
\hline ES (1): ES21; FR (2): FR62, FR71; UK (3): UKC1, UKE3, UKG3 & 0 & 0 & 0 & 0 & 1 & 0 \\
\hline BE (1): BE33; IT (1): IRC1; HU (1): HU22; UK (4): UKC2, UKD7, UKL1, UKM3 & 0 & 0 & 0 & 0 & 0 & 1 \\
\hline Ogólem & 88 & 78 & 54 & 10 & 24 & 37 \\
\hline
\end{tabular}

Źródło: opracowanie własne

Spadki stóp zatrudnienia i wzrosty stóp bezrobocia - charakterystyczne dla roku 2008 załamały właściwą grupie pierwszej tendencję wzrostów - z ponad 100 regionów w latach 2006-2007 zostało $26 \mathrm{w}$ roku 2008.

Tabela 6. Regiony w klasie piątej

\begin{tabular}{|l|c|c|c|c|c|c|}
\hline \multicolumn{1}{|c|}{ Kraj (liczba regionów z kraju): kod regionu } & \multicolumn{5}{c|}{ Przynależność regionu do klasy } \\
\cline { 2 - 6 } & $\mathbf{2 0 0 6}$ & $\mathbf{2 0 0 7}$ & $\mathbf{2 0 0 8}$ & $\mathbf{2 0 0 9}$ & $\mathbf{2 0 1 0}$ & $\mathbf{2 0 1 1}$ \\
\hline ES (2): ES61, ES62 & 0 & 1 & 1 & 0 & 1 & 1 \\
\hline ES (2): ES42, ES70 & 0 & 1 & 1 & 0 & 1 & 0 \\
\hline ES (2): ES52, ES53 & 0 & 0 & 1 & 0 & 1 & 1 \\
\hline EL (1): EL22 & 1 & 0 & 0 & 0 & 1 & 0 \\
\hline BG (1): BG33; EE00; IE(1): IE02; ES (3): ES11, ES12, ES24; LT00 & 0 & 0 & 1 & 0 & 1 & 0 \\
\hline ES (1): ES43 & 0 & 0 & 1 & 0 & 0 & 1 \\
\hline EL (4): EL11, EL12, EL13, EL30 & 0 & 0 & 0 & 0 & 1 & 1 \\
\hline $\begin{array}{l}\text { IE (1): IE01; ES (7): ES13, ES21, ES22, ES23, ES30, ES41, ES51; FR (3): FR22, } \\
\text { FR41, FR81; IT (1): ITF1; LV00; HU (2): HU21, HU22; SK (1): SK02, UK (1): } \\
\text { UKG3 }\end{array}$ & 0 & 0 & 1 & 0 & 0 & 0 \\
\hline $\begin{array}{l}\text { BG (4): BG31, BG32, BG34, BG42; EL (1): EL42; PL (1): PL34; PT (1): PT15; } \\
\text { SK (1): SK04 }\end{array}$ & 0 & 0 & 0 & 0 & 1 & 0 \\
\hline $\begin{array}{l}\text { EL (7): EL14, EL21, EL23, EL24, EL25, EL41, EL43; PT (3):PT16, PT20, PT30; } \\
\text { RO (1): RO31; UK (1): UKC1 }\end{array}$ & 0 & 0 & 0 & 0 & 0 & 1 \\
\hline \multicolumn{1}{|c|}{ Ogółem } & $\mathbf{1}$ & $\mathbf{4}$ & $\mathbf{3 1}$ & $\mathbf{0}$ & $\mathbf{2 6}$ & $\mathbf{2 1}$ \\
\hline
\end{tabular}

Źródło: opracowanie własne

Regiony polskie znalazły się w kolejnych latach w następujących grupach:

- 2006 r. - głównie w czwartej, poza podlaskim, zachodniopomorskim i kujawskopomorskim, które zaliczono do grupy drugiej; 
- 2007 r. - wszystkie w grupie czwartej;

- 2008 r. - poza lubelskim w grupie czwartej;

- 2009 r. - dziewięć regionów w grupie drugiej, ponadto pięć (łódzkie, małopolskie, podlaskie i wielkopolskie oraz pomorskie) w grupie trzeciej i po jednym w czwartej (śląskie) oraz pierwszej (mazowieckie);

- 2010 r. - z wyjątkiem mazowieckiego i pomorskiego (trzecia klasa) oraz podlaskiego (piąta) w klasie drugiej;

- 2011 r. - dziesięć regionów w klasie drugiej, a sześć w klasie czwartej (łódzkie, mazowieckie, śląskie, podlaskie, lubuskie i opolskie).

Geograficzne rozmieszczenie regionów $\mathrm{z}$ utworzonych klas w kolejnych latach przedstawiono na rysunkach 2 i 3. Na mapach widać, że regiony, które „opuściły” grupę pierwszą, znalazły się w grupie trzeciej (ze 115 w roku 2006, aż 94 w 2009 były w grupie trzeciej) i piątej (pozostałe 10). Do ,tracących” regiony w roku 2008 należy także grupa czwarta - ogólnie średnie tempa zmian były najlepsze. Znamienny jest także podział na „starą" Unię i regiony krajów ostatnich rozszerzeń oraz regiony stołeczne, które w wielu wypadkach stanowią inną niż pozostałe regiony w kraju grupę (np. Berlin w roku 2011). Na zaprezentowanych mapach zauważalny jest także podział Niemiec czy Włoch na część północną i południową.

Rysunek 2. Graficzna prezentacja wyników klasyfikacji - lata 2006-2009

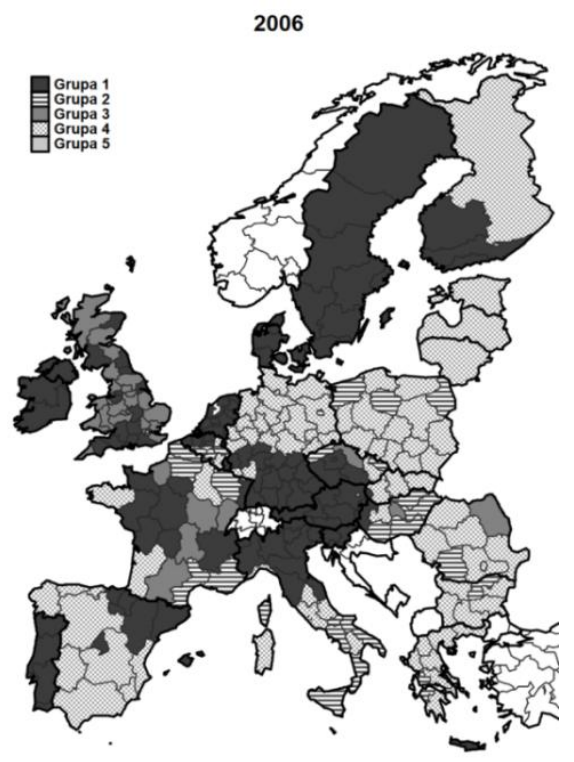



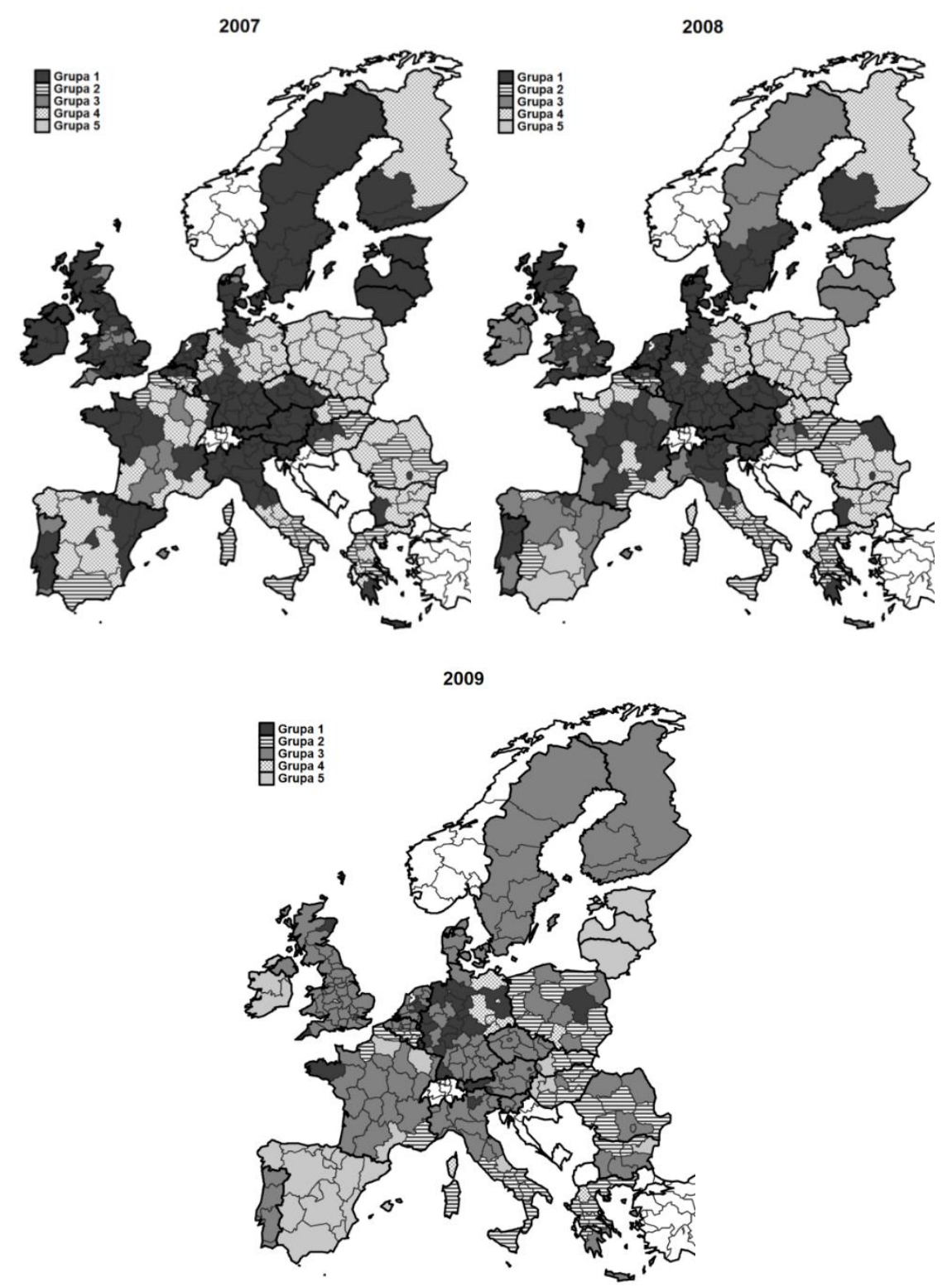

Źródło: opracowanie własne

Najbardziej spektakularna jest jednak dominacja grupy trzeciej w roku 2009 - średnia stopa zatrudnienia $68,4 \%$ i bezrobocia $6,8 \%$, przy drugim co do wielkości (najgorszym średnim tempie spadku). 
Rysunek 3. Graficzna prezentacja wyników klasyfikacji - lata 2010-2011
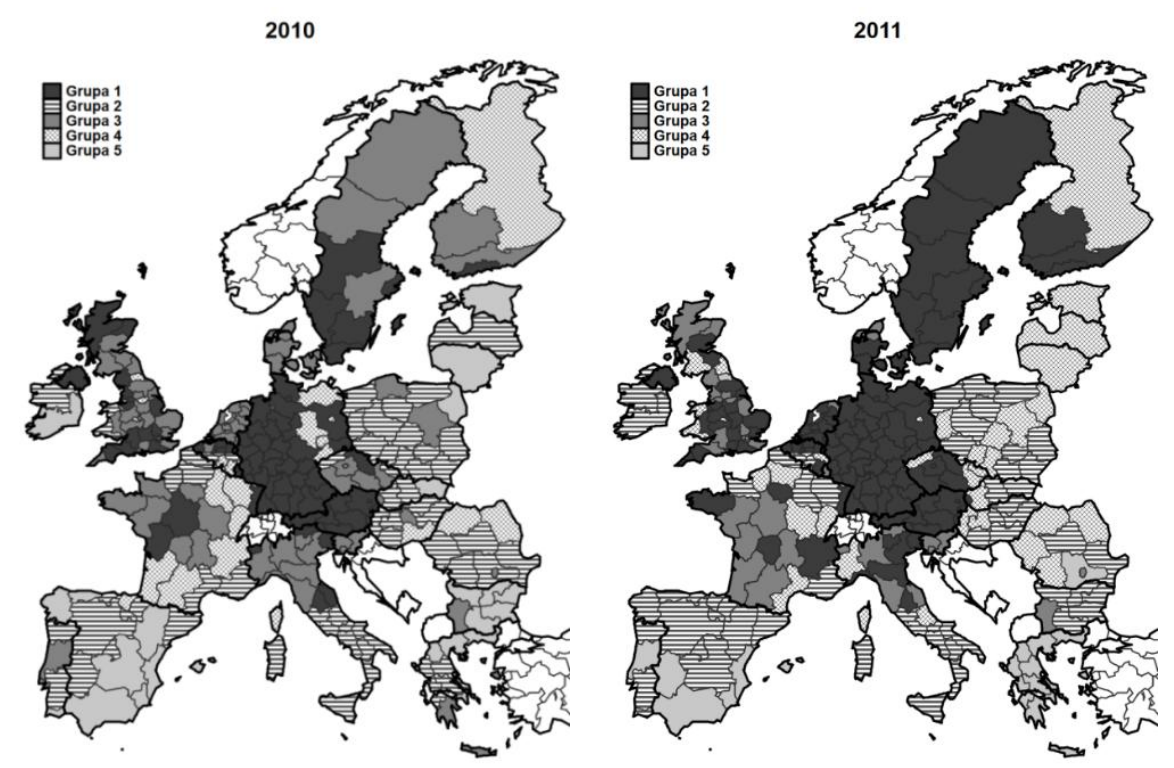

Źródło: opracowanie własne

\section{PODSUMOWANIE}

Zaprezentowane - w bardzo skrótowej wersji ze względu na ograniczenia objętości artykułu - wyniki badań pozwalają na następujące wnioski:

- zmienne wybrane do oceny wrażliwości na kryzys ekonomiczny regionów UE szczebla NUTS 2 mają znaczną zdolność diagnostyczną;

- zaproponowane podejście badawcze pozwala na wydzielenie grup regionów o podobnych właściwościach ze względu na badane charakterystyki rynku pracy;

- w otrzymanych grupach regionów niewiele obiektów jest trwale przypisanych do klasy - rynek pracy w analizowanym okresie dotknęły gwałtowne turbulencje.

Konieczne są pogłębione badania w roku newralgicznym - 2009, które pozwolą na określenie determinant wrażliwości na kryzys regionów szczebla NUTS 2.

\section{LITERATURA}

[1] Markowska M., Dynamiczna taksonomia innowacyjności regionów, Wydawnictwo Uniwersytetu Ekonomicznego we Wrocławiu, Monografie i Opracowania 221, Wrocław 2012.

[2] Markowska M., Ocena zależności między rozwojem inteligentnym a odpornościa na kryzys ekonomiczny $w$ wymiarze regionalnym - przeglad badań, [w:] Gospodarka regionalna $w$ teorii i praktyce, red. D. Strahl, A. Raszkowski, D. Głuszczuk, Prace Naukowe Uniwersytetu Ekonomicznego we Wrocławiu nr 333, Wrocław 2014, s. 22-32. 
[3] Markowska M., Ocena wrażliwości na kryzys gospodarstw domowych w unijnych regionach - analiza przestrzenno-czasowa, [w:] Problemy rozwoju regionalnego i lokalnego, red. M. Markowska, D. Głuszczuk, A. Sztando, Prace Naukowe Uniwersytetu Ekonomicznego we Wrocławiu nr 393, Wrocław 2015, s. 53-66).

[4] Markowska M., The vulnerability of regions to economic crisis - measurement problems, [w:] Regional economy and policy. Territories and cities, red. P. Hlavacek, P. Olsowa, Jan Evangelista Purkyne University in Usti nad Labem Usti nad Labem 2014, 38-47.

[5] Markowska M., Strahl D., Wykorzystanie klasyfikacji dynamicznej do identyfikacji wrażliwości na kryzys ekonomiczny unijnych regionów szczebla NUTS 2. [w:] Taksonomia, red. M. Walesiak, K. Jajuga, Prace Naukowe Uniwersytetu Ekonomicznego we Wrocławiu nr 385, Wrocław 2015, s. 38-47.

[6] Markowska M., Strahl D., Sokołowski A., Sobolewski M., Klasyfikacja dynamiczna regionów Unii Europejskiej szczebla NUTS 2 z uwagi na wrażliwość na kryzys ekonomiczny (obszar: zmiany w gospodarce), [w:] Problemy rozwoju regionalnego $i$ lokalnego, M. Markowska, D. Głuszczuk, A. Sztando (red.), Prace Naukowe Uniwersytetu Ekonomicznego we Wrocławiu nr 393, Wrocław 2015, s. 32-44.

[7] Regions in the European Union. Nomenclature of territorial unit for statistics NUTS 2010/EU-27, Methodologies and Working Papers, European Commission, Luxembourg 2011.

[8] Strahl D., Sokołowski A., Propozycja podejścia metodologicznego do oceny zależności między inteligentnym rozwojem a wrażliwościa na kryzys ekonomiczny $w$ wymiarze regionalnym, [w:] Problemy rozwoju regionalnego i lokalnego, red. E. Sobczak, B. Bal-Domańska, M. Obrębalski , Prace Naukowe Uniwersytetu Ekonomicznego we Wrocławiu nr 331, Wrocław 2014, s. 181-190.

Spis regionów:

BE10 Région de Bruxelles-Capitale, BE21 Prov. Antwerpen, BE22 Prov. Limburg, BE23 Prov. Oost-Vlaanderen, BE24 Prov. Vlaams-Brabant, BE25 Prov. West-Vlaanderen, BE31 Prov. Brabant Wallon, BE32 Prov. Hainaut, BE33 Prov. Liège, BE34 Prov. Luxembourg, BE35 Prov. Namur, BG31 Severozapaden, BG32 Severen tsentralen, BG33 Severoiztochen, BG34 Yugoiztochen, BG41 Yugozapaden, BG42 Yuzhen tsentralen, CZ01 Praha, CZ02 Strední Cechy, CZ03 Jihozápad, CZ04 Severozápad, CZ05 Severovýchod, CZ06 Jihovýchod, CZ07 Strední Morava, CZ08 Moravskoslezsko, DK01 Hovedstaden, DK02 Sjælland, DK03 Syddanmark, DK04 Midtjylland, DK05 Nordjylland, DE11 Stuttgart, DE12 Karlsruhe, DE13 Freiburg, DE14 Tübingen, DE21 Oberbayern, DE22 Niederbayern, DE23 Oberpfalz, DE24 Oberfranken, DE25 Mittelfranken, DE26 Unterfranken, DE27 Schwaben, DE30 Berlin, DE40 Brandenburg, DE50 Bremen, DE60 Hamburg, DE71 Darmstadt, DE72 Gießen, DE73 Kassel, DE80 Mecklenburg-Vorpommern, DE91 Braunschweig, DE92 Hannover, DE93 Lüneburg, DE94 Weser-Ems, DEA1 Düsseldorf, DEA2 Köln, DEA3 Münster, DEA4 Detmold, DEA5 Arnsberg, DEB1 Koblenz, DEB2 Trier, DEB3 Rheinhessen-Pfalz, DEC0 Saarland, DED2 Dresden, DED4 Chemnitz, DED5 Leipzig, DEE0 Sachsen-Anhalt, DEF0 Schleswig-Holstein, DEG0 Thüringen, EE00 Eesti, IE01 Border, Midland and Western, IE02 Southern and Eastern, EL11 Anatoliki Makedonia, Thraki, EL12 Kentriki Makedonia, EL13 Dytiki Makedonia, EL14 Thessalia, EL21 Ipeiros, EL22 Ionia Nisia, EL23 Dytiki Ellada, EL24 Sterea Ellada, EL25 Peloponnisos, EL30 Attiki, EL41 Voreio Aigaio, EL42 Notio Aigaio, EL43 Kriti, ES11 Galicia, ES12 Principado de Asturias, ES13 Cantabria, ES21 País Vasco, ES22 Comunidad Foral de Navarra, ES23 La Rioja, ES24 Aragón, ES30 Comunidad de Madrid, 
ES41 Castilla y León, ES42 Castilla-la Mancha, ES43 Extremadura, ES51 Cataluña, ES52 Comunidad Valenciana, ES53 Illes Balears, ES61 Andalucía, ES62 Región de Murcia, ES70 Canarias, FR10 Île de France, FR21 Champagne-Ardenne, FR22 Picardie, FR23 Haute-Normandie, FR24 Centre, FR25 Basse-Normandie, FR26 Bourgogne, FR30 Nord - Pas-de-Calais, FR41 Lorraine, FR42 Alsace, FR43 Franche-Comté, FR51 Pays de la Loire, FR52 Bretagne, FR53 PoitouCharentes, FR61 Aquitaine, FR62 Midi-Pyrénées, FR63 Limousin, FR71 Rhône-Alpes, FR72 Auvergne, FR81 Languedoc-Roussillon, FR82 Provence-Alpes-Côte d'Azur, FR83 Corse, ITC1 Piemonte, ITC2 Valle d'Aosta, ITC3 Liguria, ITC4 Lombardia, ITH1 Provincia Autonoma di Bolzano, ITH2 Provincia Autonoma di Trento, ITH3 Veneto, ITH4 Friuli-Venezia Giulia, ITH5 Emilia-Romagna, ITI1 Toscana, ITI2 Umbria, ITI3 Marche, ITI4 Lazio, ITF1 Abruzzo, ITF2 Molise, ITF3 Campania, ITF4 Puglia, ITF5 Basilicata, ITF6 Calabria, ITG1 Sicilia, ITG2 Sardegna, CY00 Kypros, LV00 Latvia, LT00 Lithuania, LU00 Luxembourg, HU10 Közép-Magyarország, HU21 Közép-Dunántúl, HU22 Nyugat-Dunántúl, HU23 Dél-Dunántúl, HU31 Észak-Magyarország, HU32 Észak-Alföld, HU33 Dél-Alföld, MT00 Malta, NL11 Groningen, NL12 Friesland, NL13 Drenthe, NL21 Overijssel, NL22 Gelderland, NL23 Flevoland, NL31 Utrecht, NL32 NoordHolland, NL33 Zuid-Holland, NL34 Zeeland, NL41 Noord-Brabant, NL42 Limburg, AT11 Burgenland, AT12 Niederösterreich, AT13 Wien, AT21 Kärnten, AT22 Steiermark, AT31 Oberösterreich, AT32 Salzburg, AT33 Tirol, AT34 Vorarlberg, PL11 Łódzkie, PL12 Mazowieckie, PL21 Małopolskie, PL22 Śląskie, PL31 Lubelskie, PL32 Podkarpackie, PL33 Świętokrzyskie, PL34 Podlaskie, PL41 Wielkopolskie, PL42 Zachodniopomorskie, PL43 Lubuskie, PL51 Dolnośląskie, PL52 Opolskie, PL61 Kujawsko-pomorskie, PL62 Warmińsko-mazurskie, PL63 Pomorskie, PT11 Norte, PT15 Algarve, PT16 Centro, PT17 Lisboa, PT18 Alentejo, PT20 Região Autónoma dos Açores, PT30 Região Autónoma da Madeira, RO11 Nord-Vest, RO12 Centru, RO21 Nord-Est, RO22 Sud-Est, RO31 Sud - Muntenia, RO32 Bucuresti - Ilfov, RO41 Sud-Vest Oltenia, RO42 Vest, SI01 Vzhodna Slovenija, SI02 Zahodna Slovenija, SK01 Bratislavský kraj, SK02 Západné Slovensko, SK03 Stredné Slovensko, SK04 Východné Slovensko, FI19 Länsi-Suomi, FI1B Helsinki-Uusimaa, FI1C Etelä-Suomi, FI1D Pohjois-ja Itä-Suomi, FI20 Åland, SE11 Stockholm, SE12 Östra Mellansverige, SE21 Småland med öarna, SE22 Sydsverige, SE23 Västsverige, SE31 Norra Mellansverige, SE32 Mellersta Norrland, SE33 Övre Norrland, UKC1 Tees Valley and Durham, UKC2 Northumberland and Tyne and Wear, UKD1 Cumbria, UKD3 Greater Manchester, UKD4 Lancashire, UKD6 Cheshire, UKD7 Merseyside, UKE1 East Yorkshire and Northern Lincolnshire, UKE2 North Yorkshire, UKE3 South Yorkshire, UKE4 West Yorkshire UKF1 Derbyshire and Nottinghamshire, UKF2 Leicestershire, Rutland and Northamptonshire, UKF3 Lincolnshire, UKG1 Herefordshire, Worcestershire and Warwickshire, UKG2 Shropshire and Staffordshire, UKG3 West Midlands, UKH1 East Anglia, UKH2 Bedfordshire and Hertfordshire, UKH3 Essex, UKI1 Inner London, UKI2 Outer London, UKJ1 Berkshire, Buckinghamshire and Oxfordshire, UKJ2 Surrey, East and West Sussex, UKJ3 Hampshire and Isle of Wight, UKJ4 Kent, UKK1 Gloucestershire, Wiltshire and Bristol, UKK2 Dorset and Somerset, UKK3 Cornwall and Isles of Scilly, UKK4 Devon, UKL1 West Wales and The Valleys, UKL2 East Wales, UKM2 Eastern Scotland, UKM3 South Western Scotland, UKM5 North Eastern Scotland, UKM6 Highlands and Islands, UKNO Northern Ireland

\section{DYNAMIC CLASSIFICATION OF THE EUROPEAN UNION NUTS 2 REGIONS IN TERMS OF SENSITIVITY TO ECONOMIC CRISIS (AREA: LABOUR MARKET)}

The assessment of reasons and effects of economic crisis may cover various levels of management. It is possible to conduct analyses at macro level and also at intermediate levels (i.e. at the level of enterprises and in regional scale). Each of these perspectives is characterized by its specificity defining both factors and determinants of sensitivity to crisis 
regarding the analysed economies of countries, companies or regions. In terms of, among others, measurement possibilities (statistical data the range of which is different due to e.g. public statistics possibilities) it is also indispensable to take separate research approaches, typical for a given level.

Within the framework of the suggested research approach towards sensitivity areas to economic crisis of regions the following spheres were included: economy, households and labour market.

The study presents the results of dynamic classification (analysed period 2005-2011) of the European Union NUTS 2 regions in one out of the three areas of sensitivity to economic crisis: labour market. The following diagnostic variables were considered: employment rate, unemployment rate and the rate of changes characteristic for both indicators. The applied dynamic approach (which assumes that the same analysed objects (regions) are repeatedly present in the classified set and are referred to as separate taxonomic units (object-periods) in terms of their characteristics values realization in the subsequent years). Such approach allowed to distinguish the groups of regions featuring similar properties regarding the analysed characteristics of sensitivity to economic crisis, as well as facilitated the assessment of changes in assigning regions to particular classes over time.

Keywords: NUTS 2 regions, dynamic classification, vulnerability to crisis.

DOI:10.7862/rz.2015.hss.18

Przesłano do redakcji: marzec 2015

Przyjęto do druku: lipiec 2015 